\title{
Towards a Holistic Understanding
}

of the Human Genome

\section{by Determination and Integration of its}

\section{Three-Dimensional and Sequential Organization}

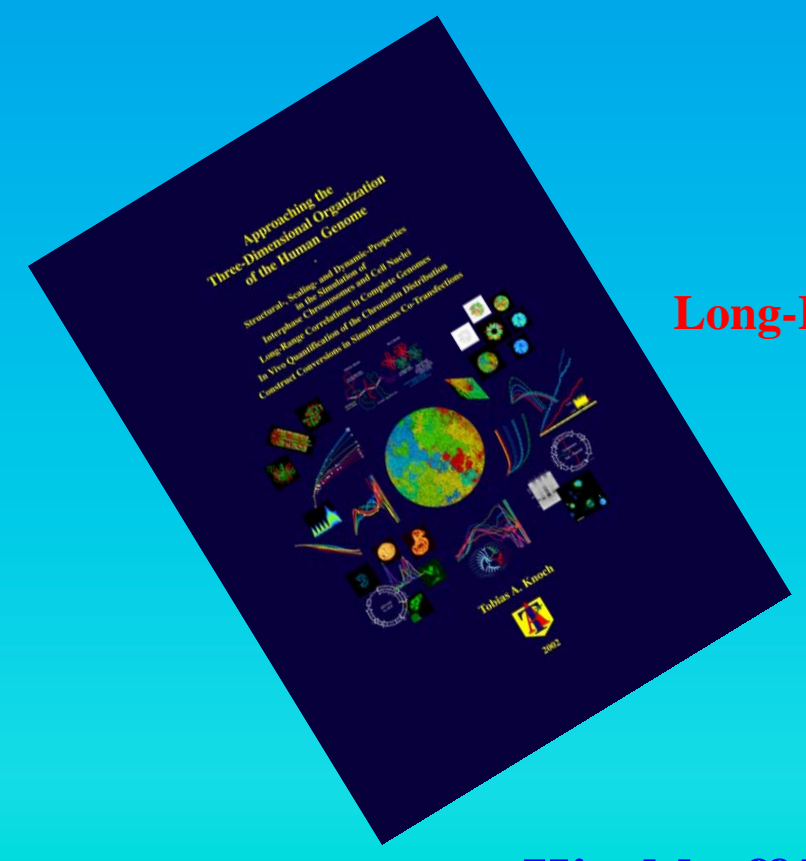

\section{Structural-, Scaling and Dynamic-Properties}

in the Simulation of

Interphase Chromosomes and Cell Nuclei

Kirchhoff Institut for Physics, Ruperto-Carola University

\&

Deutsches Krebsforschungszentrum (DKFZ)

Heidelberg

Germany 


\section{Dynamic and Hierarchical Genome Organization}

10 and 13 orders of magnitude concerning length and time scales are bridged.

Are and how are all of these organization levels connected to fullfill their obvious functions, e. $g$. gene regulation or replication, since they are optimized by evolution?

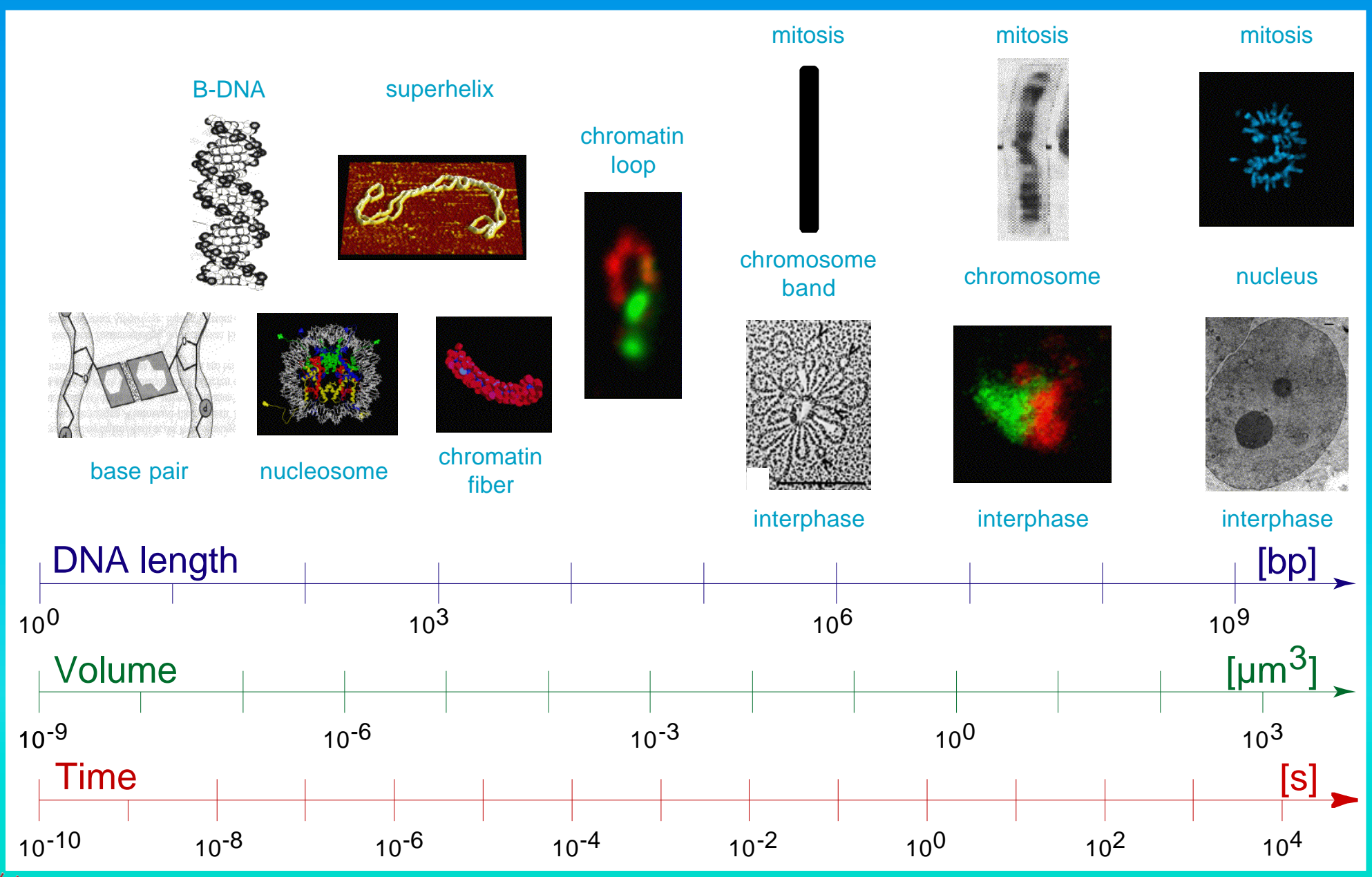




\section{Simulated Interphase Chromosome Models}

\section{Random-Walk/Giant-Loop (RW/GL) and Multi-Loop-Subcompatment (MLS) Model}

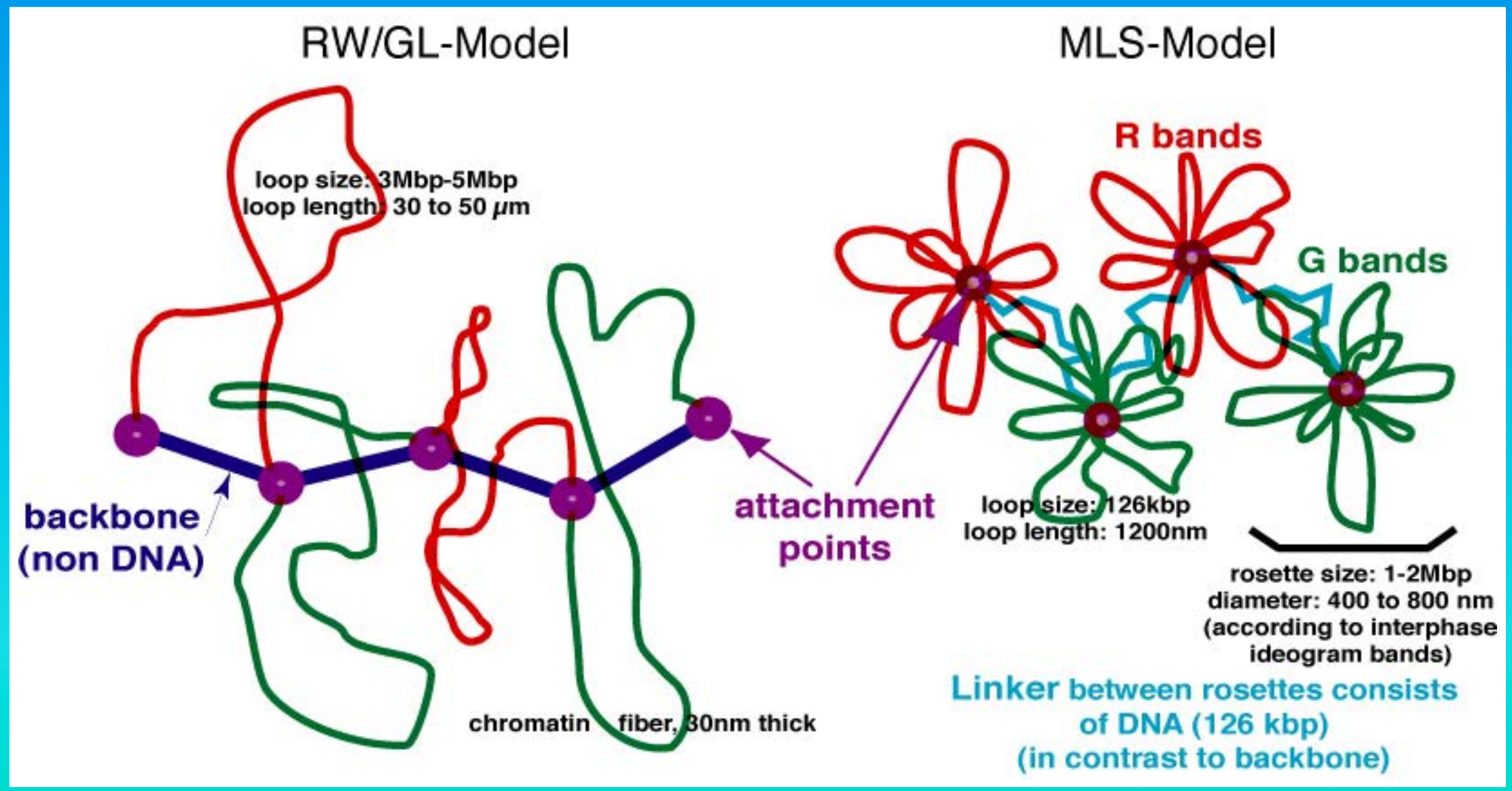




\section{Simulation of Single Chromosomes}

The $30 \mathrm{~nm}$ chromatin fiber is modeled as a polymer chain with stretching, bending, and excluded volume interactions. Monte Carlo and Brownian Dynamic methods lead to thermodynamical equilibrium configurations.

All models form chromosome territories with big voids and different chromatin morphologies. Experimental territory and subcompartment diameters agree best with an MLS model with 80 to $120 \mathrm{kbp}$ loops and linkers.

Metaphase starting configuration with

ideogram bands in red/green, linker in grey.

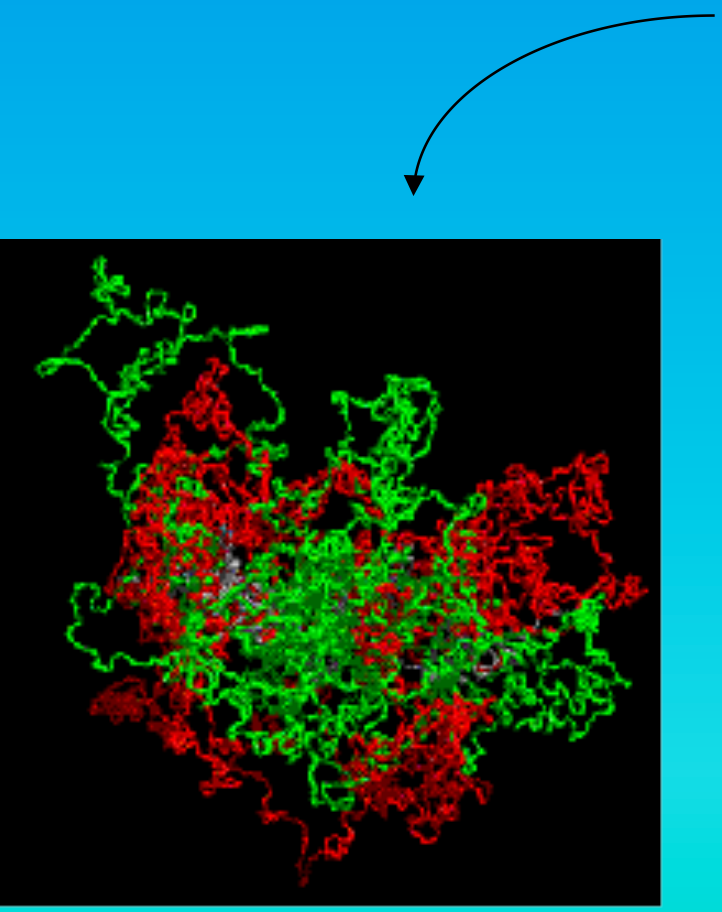

RW/GL model, loop size $5 \mathrm{Mbp}$, after $\sim 80.000 \mathrm{MC}$ and 1000 relaxing BD steps. 2. barge loops intermingle freely and reach out 2. 0 of the chromsome territory, thus forming no y. distnct features like in MLS model. (1) 12

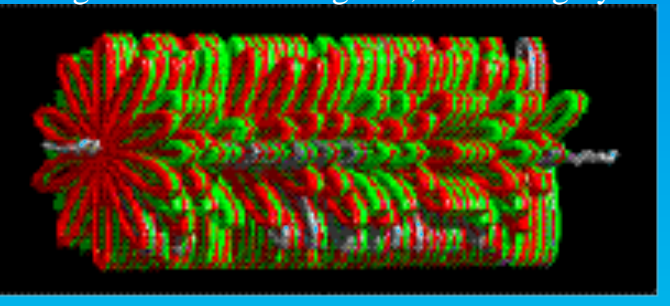

$\downarrow$

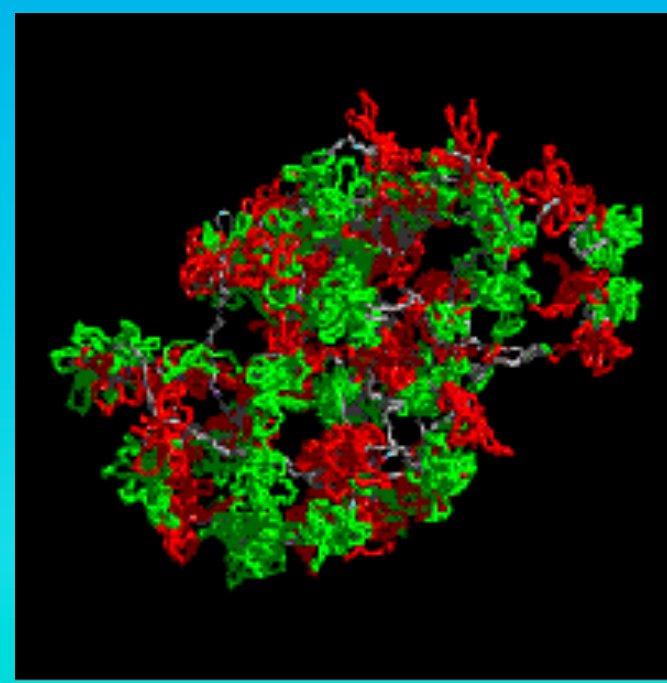

MLS model, loop size $126 \mathrm{kbp}$, linker size $126 \mathrm{kbp}$, after $\sim 50.000 \mathrm{MC}$ and 1000 relaxing $\mathrm{BD}$ steps. Here rosettes form subcompartments as separated organizational and dynamic entities.
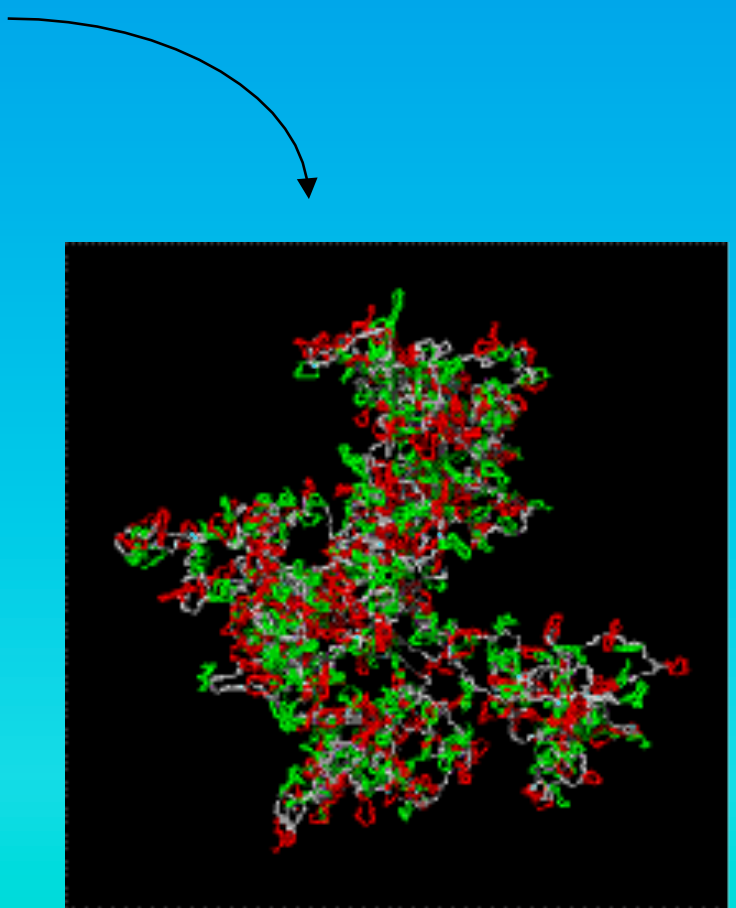

RW/GL model, loop size $126 \mathrm{kbp}$, after $\sim 80.000 \mathrm{MC}$ and 1000 relaxing BD steps. Large loops intermingle freely thus forming no distinct features like in MLS model. 


\section{Simulation of Single Chromosomes}

The $30 \mathrm{~nm}$ chromatin fiber is modeled as a polymer chain with stretching, bending, and excluded volume interactions. Monte Carlo and Brownian Dynamic methods lead to thermodynamical equilibrium configurations.

All models form chromosome territories with big voids and different chromatin morphologies. Experimental territory and subcompartment diameters agree best with an MLS model with 80 to $120 \mathrm{kbp}$ loops and linkers.

Metaphase starting configuration with

ideogram bands in red/green, linker in grey.

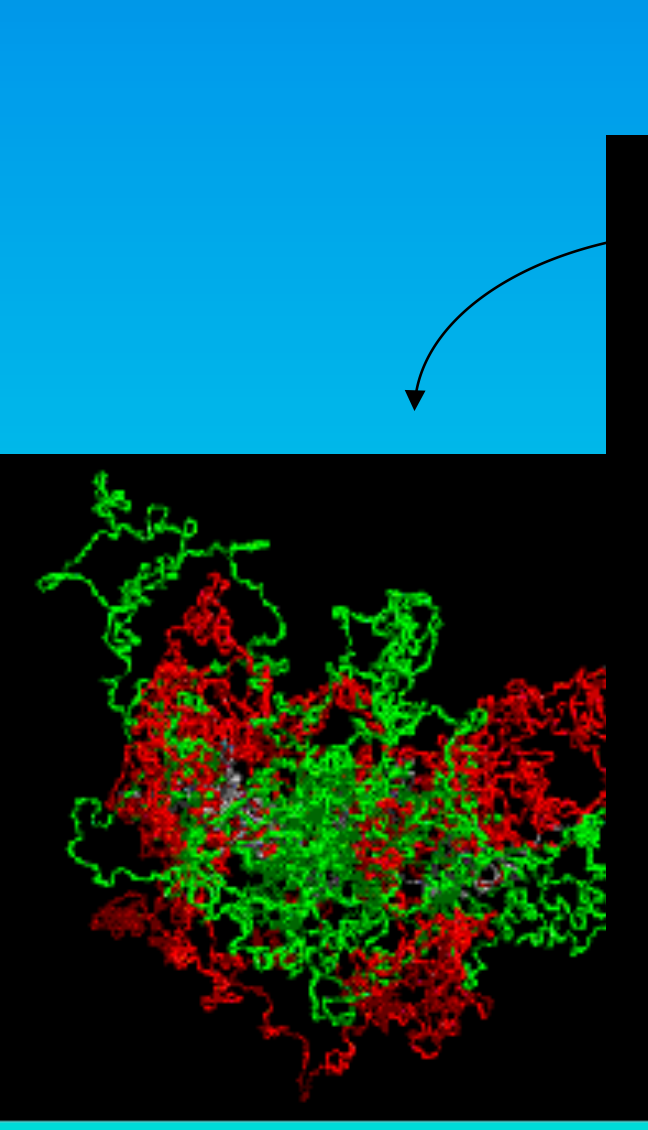

RW/GL model, loop size $5 \mathrm{Mbp}$, after $\sim 80.000 \mathrm{MC}$ and 1000 relaxing BD steps. barge loops intermingle freely and reach out 20 rof the chromsome territory, thus forming no y. distinct features like in MLS model. s.

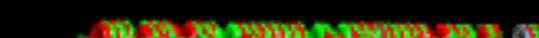
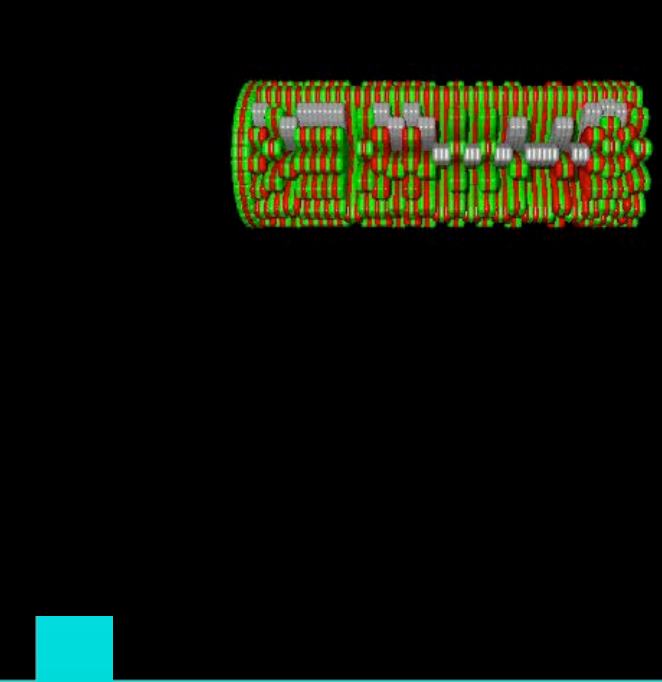

\section{126}

MLS model, loop size $126 \mathrm{~kb}$, linker size relaxing $\mathrm{BD}$ steps. Here rosettes form subcompartments as separated organizational and dynamic entities.
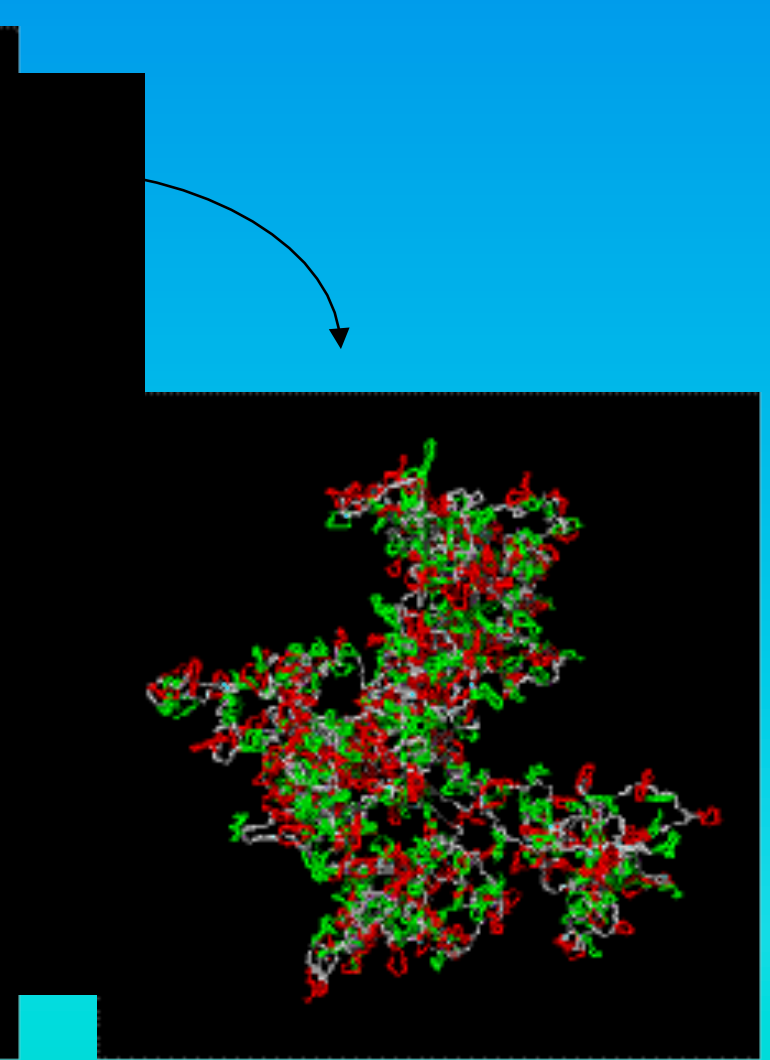

RW/GL model, loop size $126 \mathrm{kbp}$, after $\sim 80.000 \mathrm{MC}$ and 1000 relaxing BD steps. Large loops intermingle freely thus forming no distinct features like in MLS model. 


\section{Spatial Distances between Genetic Markers}

Simulated spatial distances between random genetic markers as function of their genetic separation leads to best agreement in a comparison to experiments for an MLS model with 80 to $120 \mathrm{kbp}$ loops and linkers.

The spatial distance distributions are also model characteristic and show in a set of markers as function of their relative position to the chromatin fiber topology characteristic variation, strongly connected.
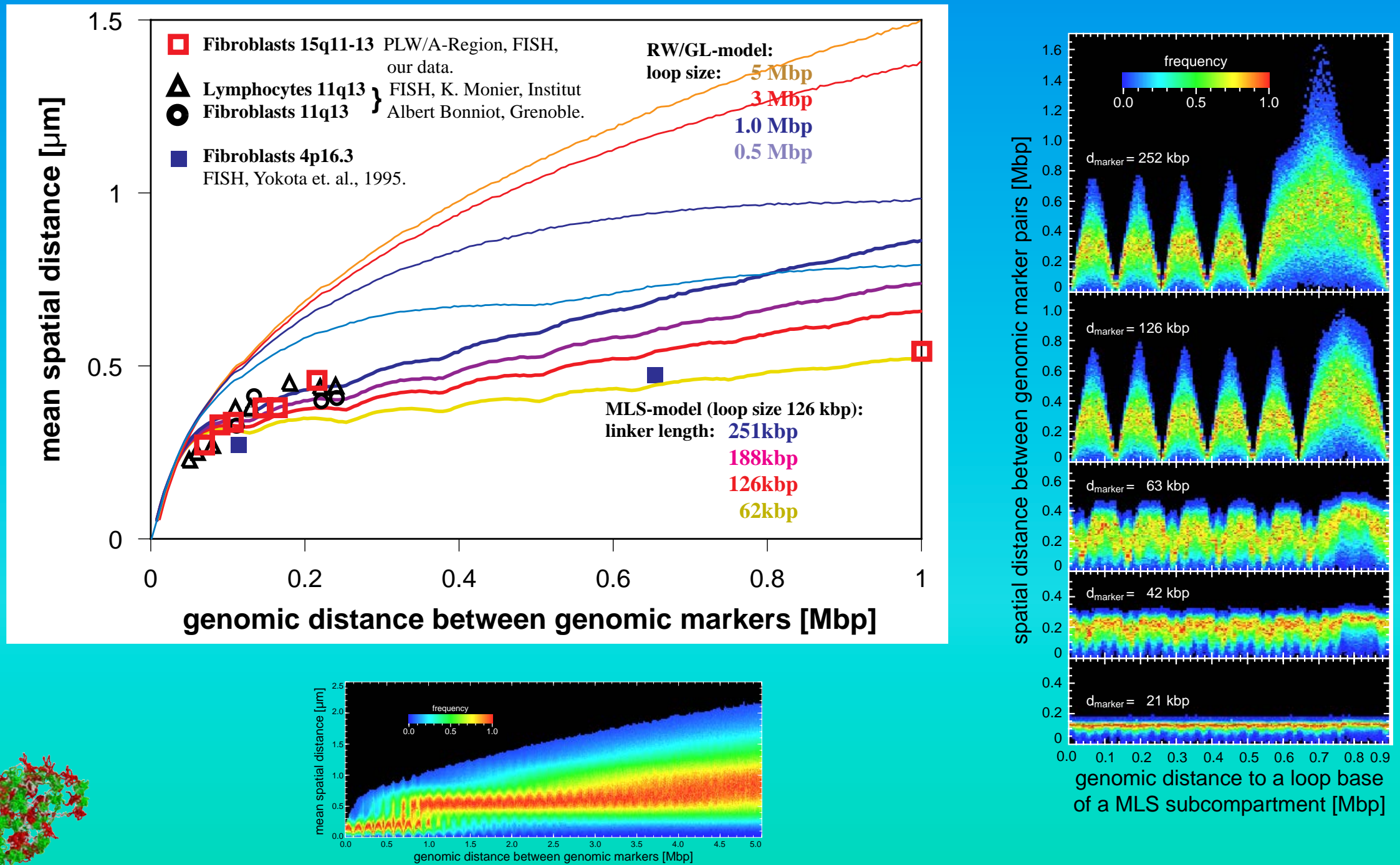
of a MLS subcompartment [Mbp] 


\section{Simulation of Whole Nuclei with all 46 Chromosomes}

Starting with some metaphase arrangement of cylindrical chromosomes, interphase nuclei with a $30 \mathrm{~nm}$ fiber resolution and at thermodynamical equilibrium are created in 4 steps using simulated annealing and Brownian Dynamics methods with stretching, bending, excluded volume and a spherical boundary interactions.

The chromosome territory position depends on their metaphase position and is reasonably stable.
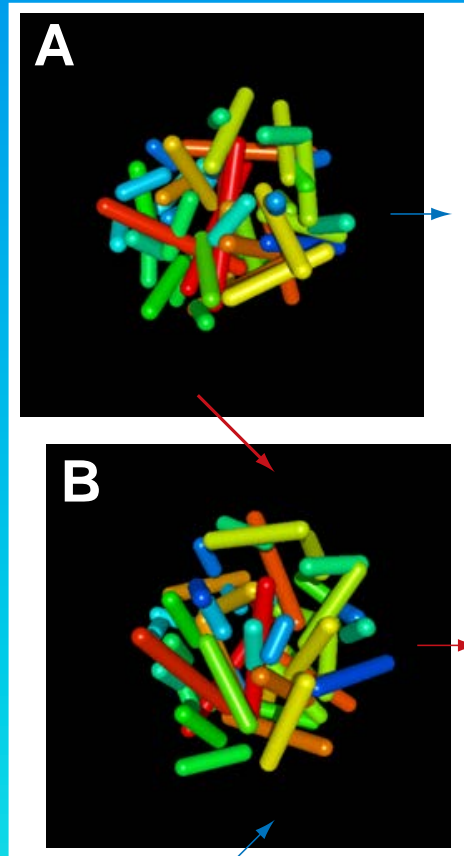

C

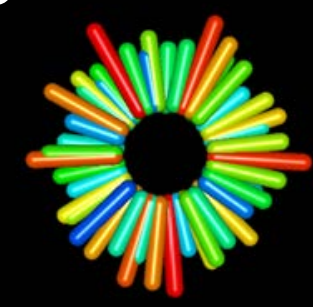

D

$$
t=
$$
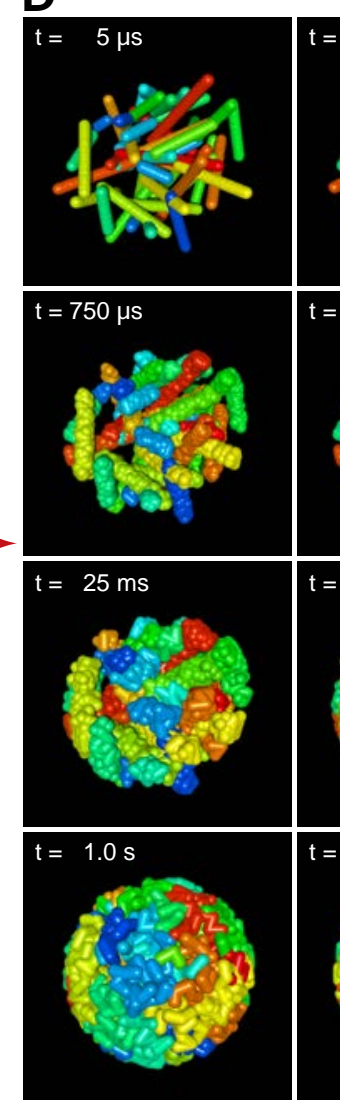
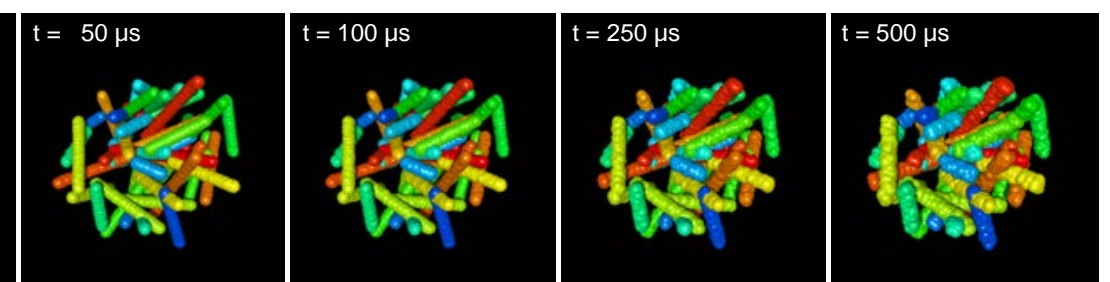

$t=1.0 \mathrm{~ms}$
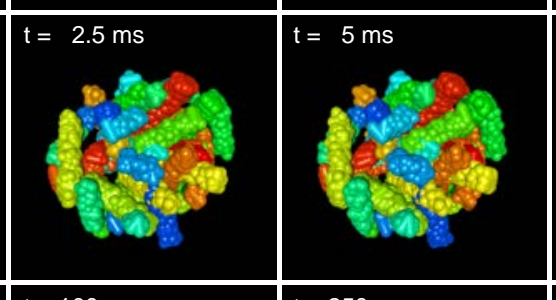

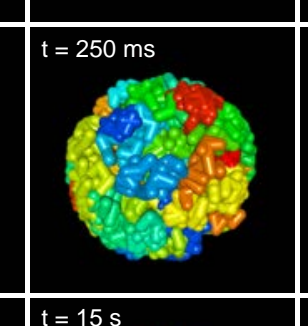

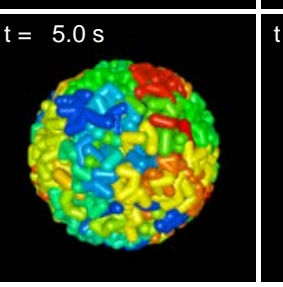
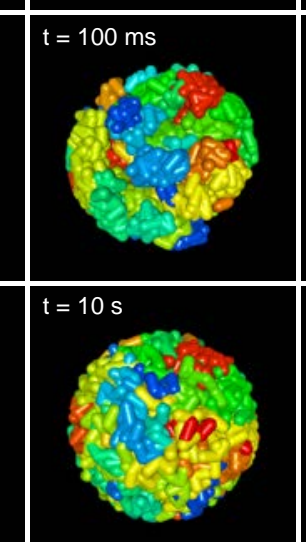

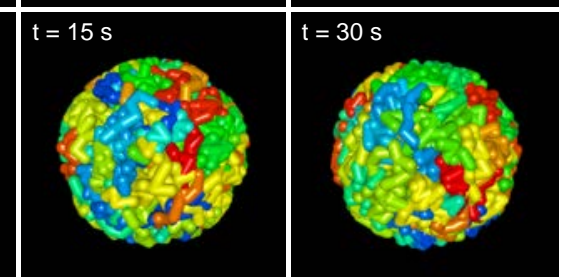

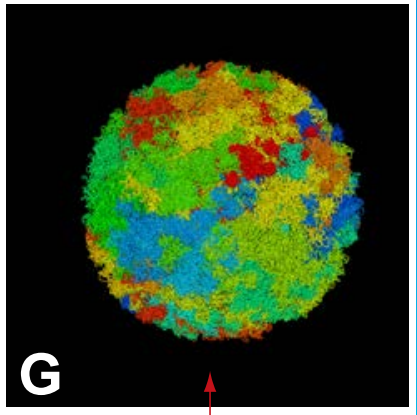

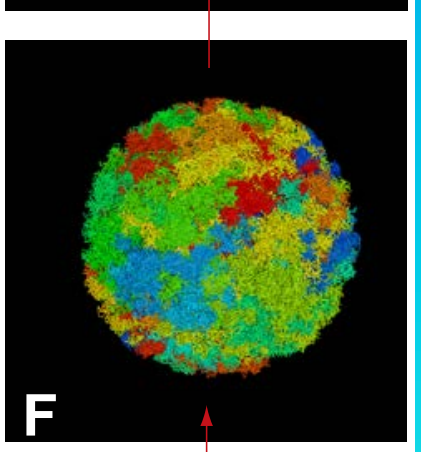




\section{Simulation of Whole Nuclei with all 46 Chromosomes}

Starting with some metaphase arrangement of cylindrical chromosomes, interphase nuclei with a $30 \mathrm{~nm}$ fiber resolution and at thermodynamical equilibrium are created in 4 steps using simulated annealing and Brownian Dynamics methods with stretching, bending, excluded volume and a spherical boundary interactions.

The chromosome territory position depends on their metaphase position and is reasonably stable.

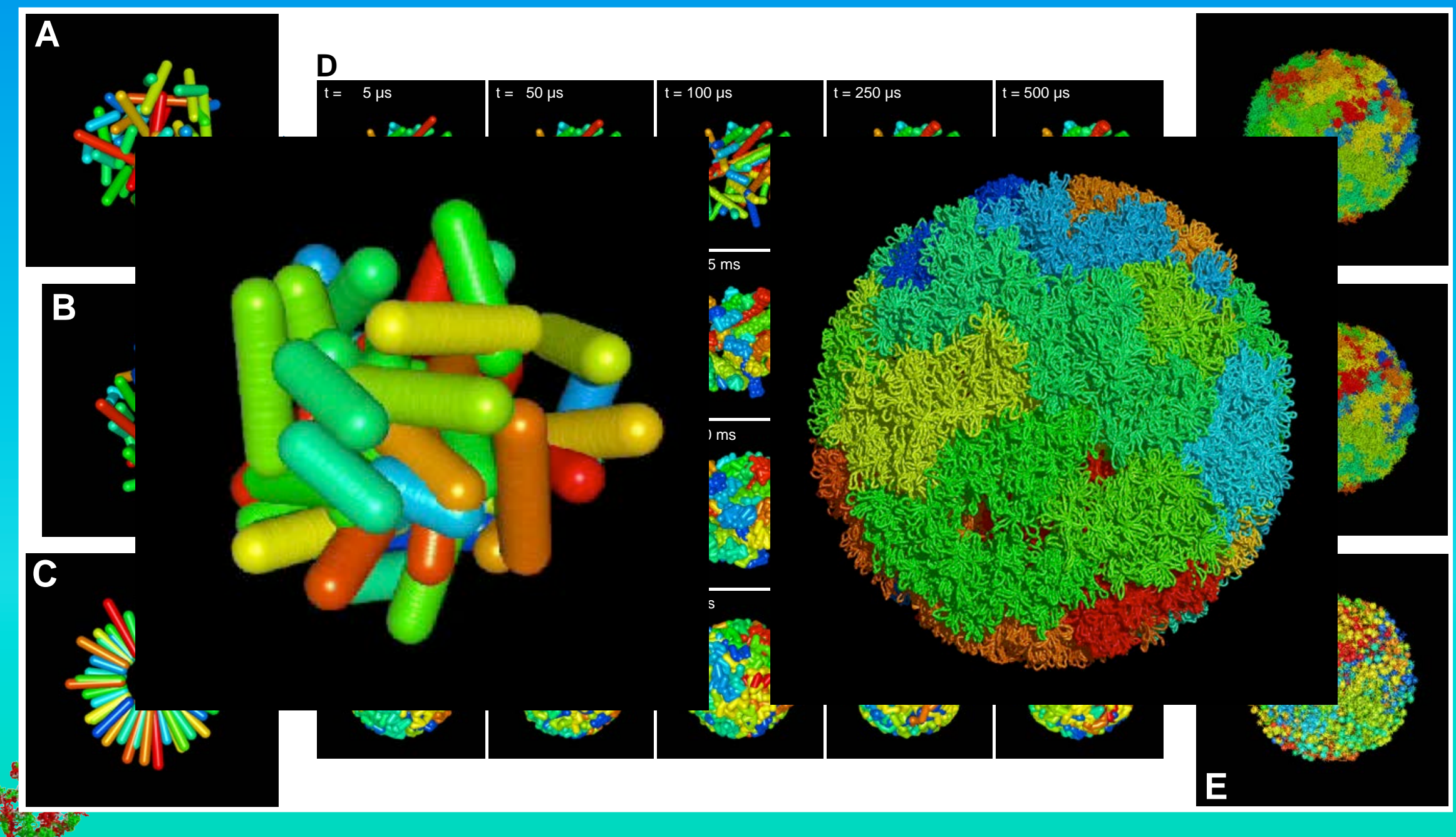




\section{From Fiber Topology to Nuclear Morphology}

Chromosome territories form in the RW/GL and the MLS model. However, only the MLS model leads distinct subcompartments and low chromosome and subcompartment overlap. Best agreement is reached for an MLS model with 80 to $120 \mathrm{kbp}$ loops and linkers in nuclei with 8 to $10 \mu \mathrm{m}$ diameter.

The simulated nuclear morphology reflects the chromosome fiber topology of different models in detail.

rendering

electron microscopy

confocal microscopy 100x objective, theoretic resolution

confocal microscopy $63 x$ objective, real resolution

confocal microscopy territory painting

electron microscopy territory painting
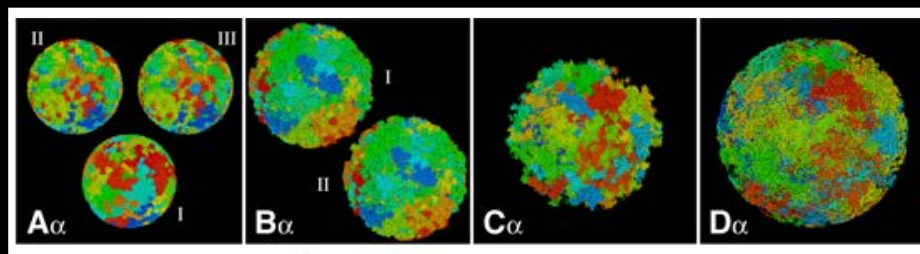
I

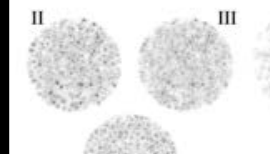

$$
\text { A }
$$

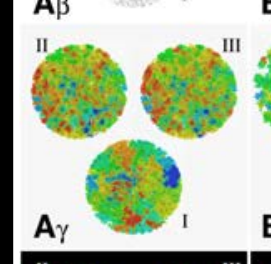

$\mathbf{B} \beta$

$\mathrm{C}_{\beta}$

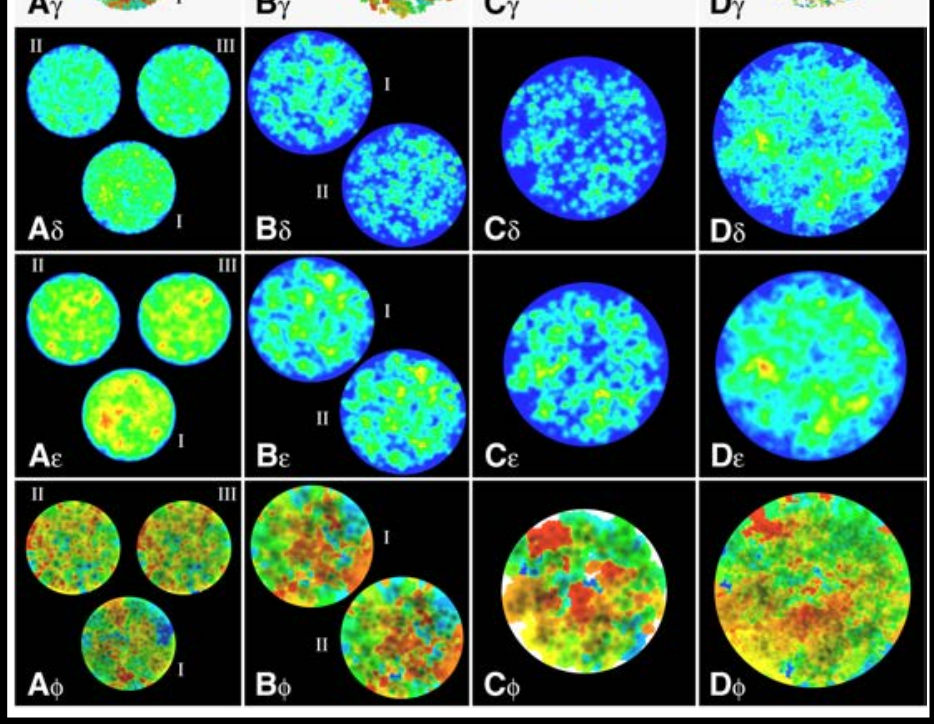

D $\beta$

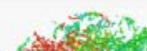
1. Dits $D_{1}$

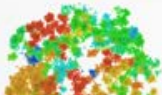
+x: $+x$ -
A: MLS in $6 \mu \mathrm{m}$ nucleus

I: $63 \mathrm{kbp}$ loops, $63 \mathrm{kbp}$ linkers II: $63 \mathrm{kbp}$ loops, $252 \mathrm{kbp}$ linkers III: 126 kbp loops, 252 kbp linkers

B: MLS in $8 \mu \mathrm{m}$ nucleus I: $126 \mathrm{kbp}$ loops, $126 \mathrm{kbp}$ linkers II: $84 \mathrm{kbp}$ loops, $126 \mathrm{kbp}$ linkers

C: MLS in $10 \mu \mathrm{m}$ nucleus $126 \mathrm{kbp}$ loops, $126 \mathrm{kbp}$ linker, not totally relaxed

D: RW/GL in $12 \mu \mathrm{m}$ nucleus 5 Mbp loops not totally relaxed

Homologous Chromosome Painting $1{ }^{3} 4^{5} 6^{7}{ }_{8}{ }^{9} 10^{11} 12^{13} 14^{15} 16^{17}{ }_{18}{ }^{19} 20^{21} 2$ 


\section{In vivo Morphology \& Chromatin Distribution}

The stable expression of fusions between histones and autofluorescent proteins and the integration into nucleosomes allows the minimal invasive investigation of the structure and dynamics of chromatin.

The clustered morphology in detail favour an MLS like chromatin topology.

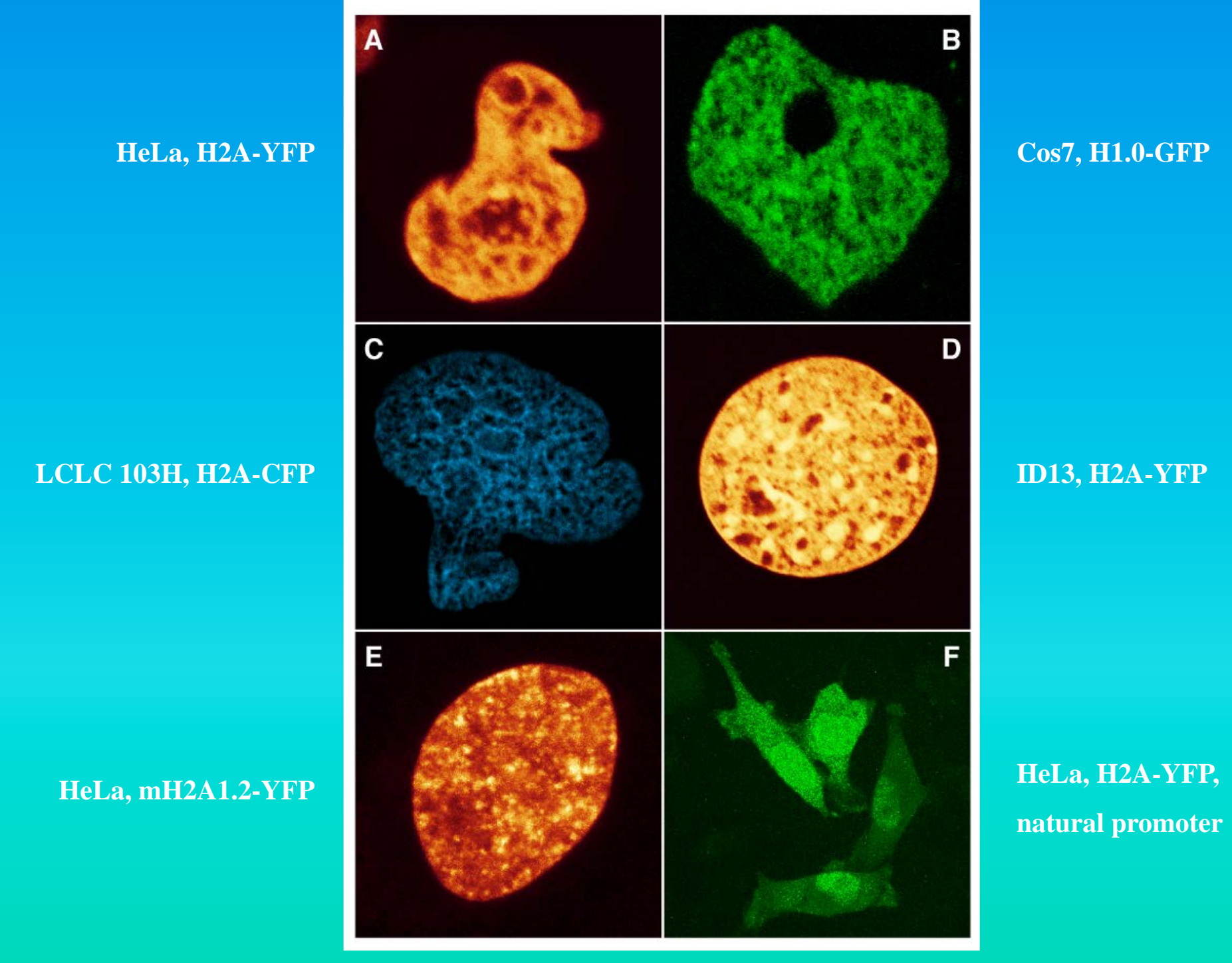




\section{Fine Morphology of Nuclei}

High resolution rendering and simulated electron microscopy including territory painting reveal not only again the model details but also that any location in the nucleus is accessible to biological molecules $<15 \mathrm{~nm}$ in diameter and that even the Extended Interchromosomal Domain hypothesis is oversimplified.
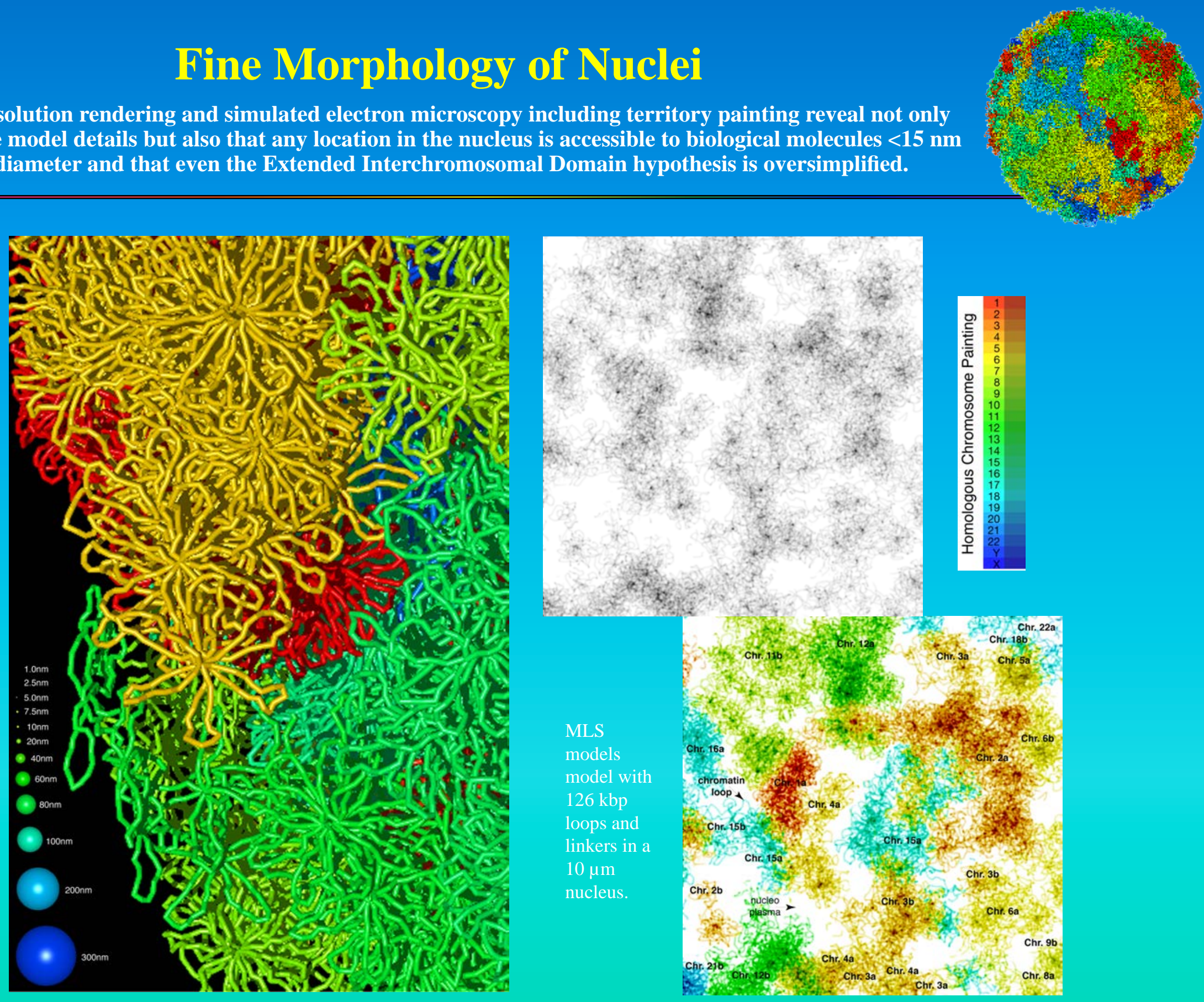


\section{Scaling of the Chromatin Fiber Topology}

The spatial-distance and exact yard-stick dimension distinguish between the simulated models in detail.The MLS model shows a globular and fine-structured multi scaling behaviour due to the loops froming rosettes.

This agrees with DNA fragmentation by Carbon ion irradiation and the appearance of fine-structured multiscaling long-range correlations found in the sequential organization of genomes.
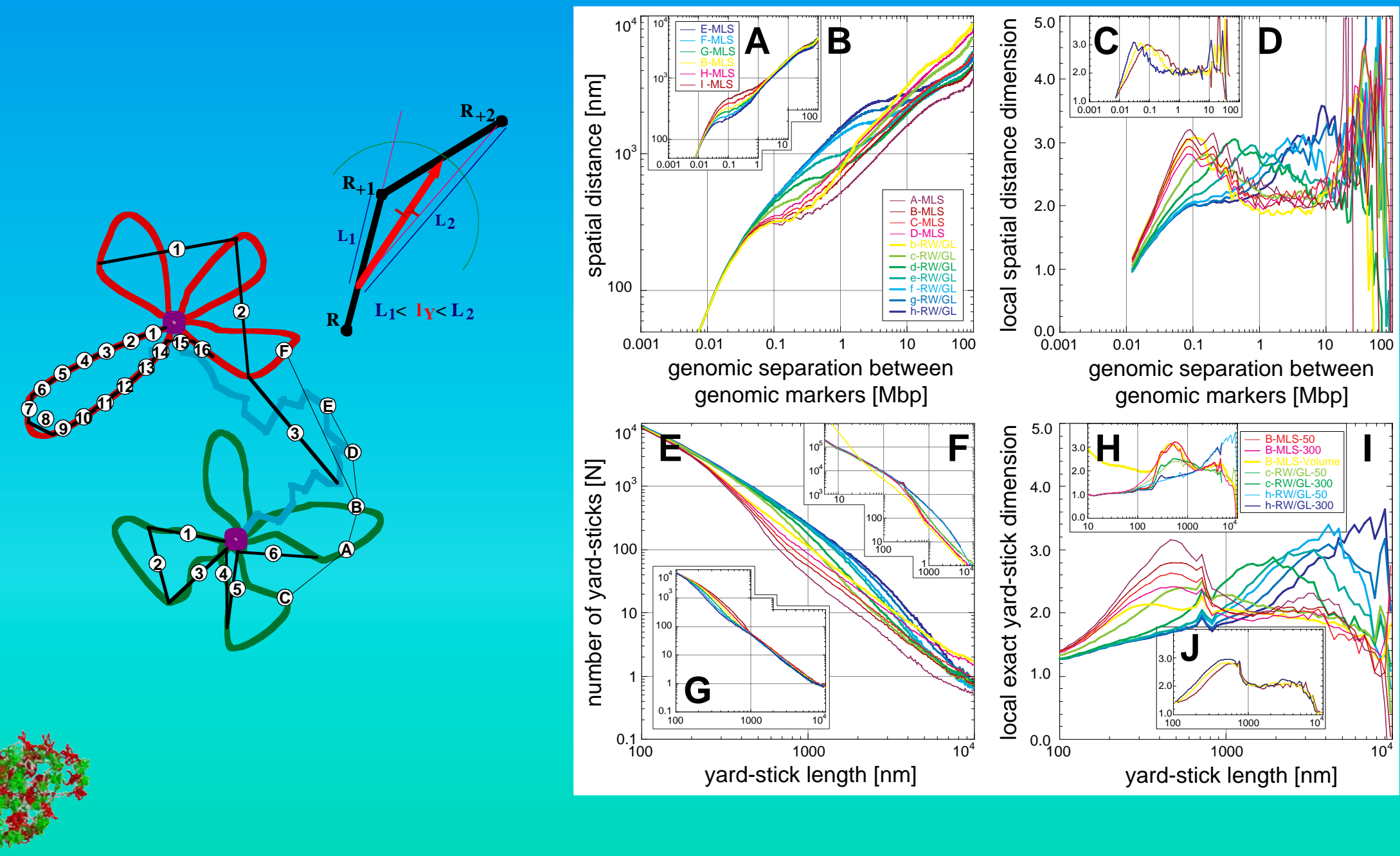


\section{Scaling of the Chromatin Morphology \& Distribution}

The local (inverse-) mass dimension distribution distinguishs between the models in detail and show also a multi-scaling behaviour with globular feature for the MLS model like the scaling of the fiber topology. With the mass dimension as function of intensity separates very well between different nuclei in vivo.

Consequently, the chromatin morphology is causally and quantitatively connected to the fiber topology.
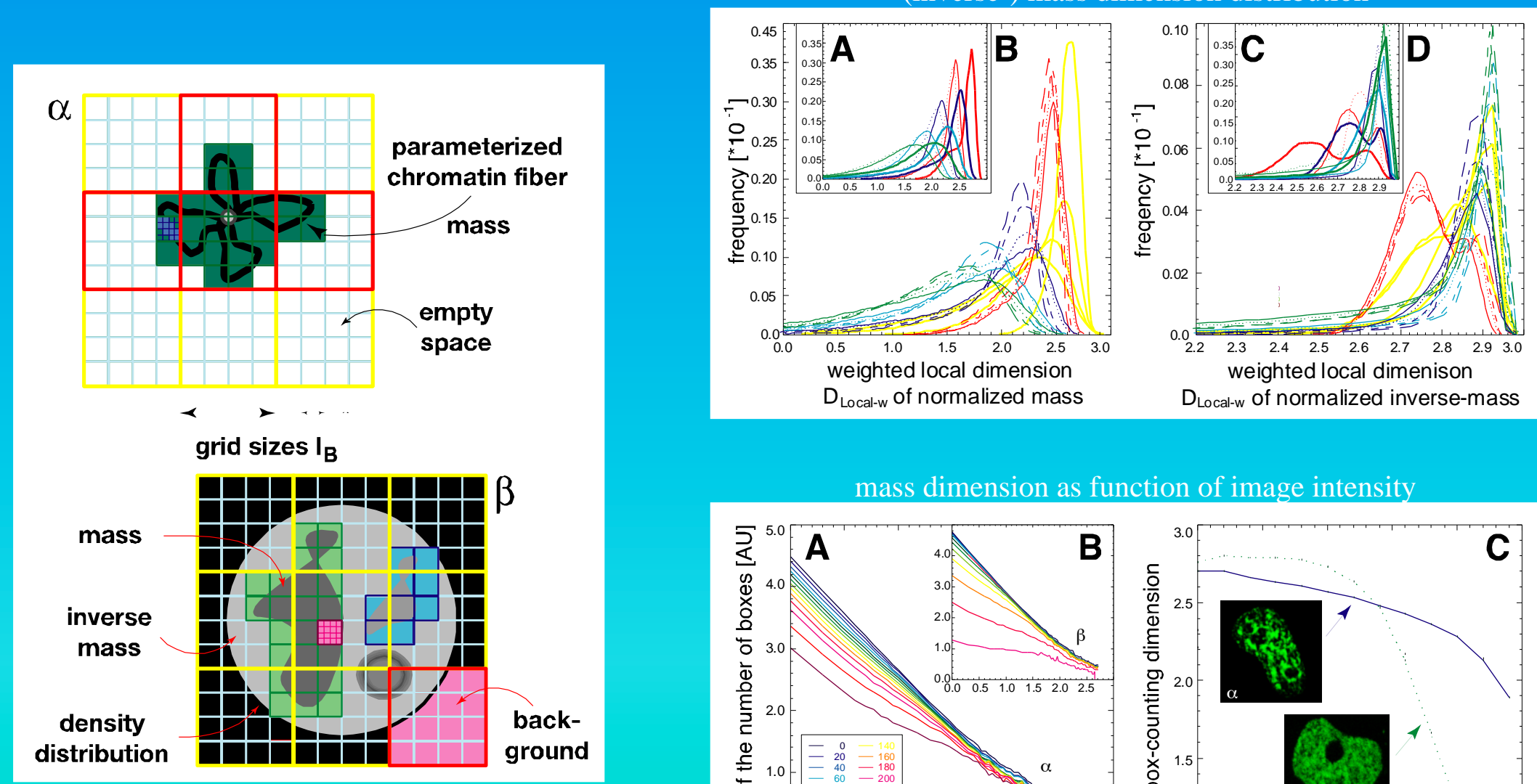

mass dimension as function of image intensity
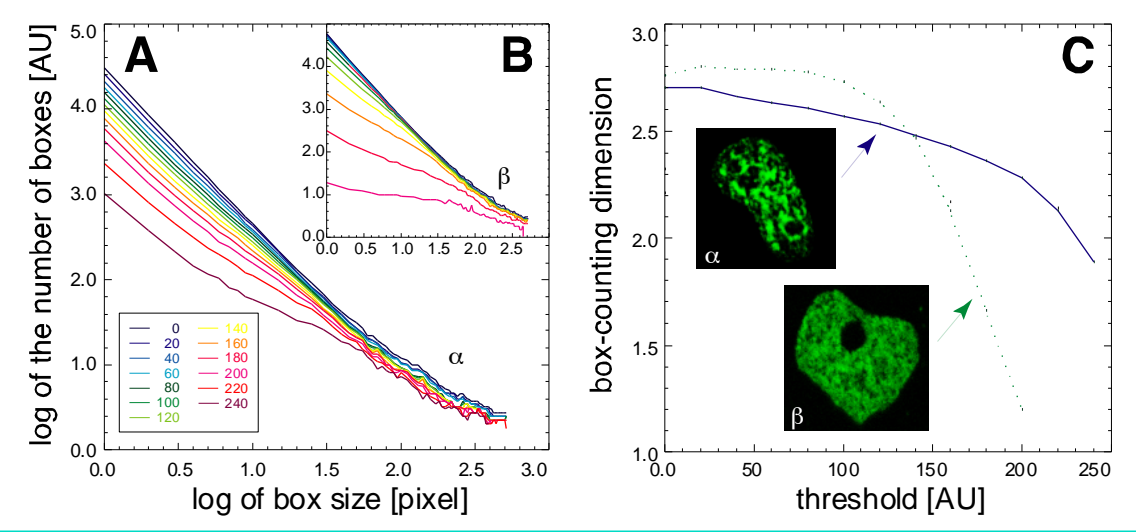
DNA Fragment Distribution after Ione-Irradiation

The length distribution of DNA fragments after irradiation with e. g. C or Ca with an inhomogeneous spatial double strand breackage probability depends on the detailed folding topology of the chromatin fiber and the RW/GL and MLS models differ largely.

Experiments always agree best with the MLS model independent of the irradiation conditions. 


\section{DNA Fragment Distribution after Ione-Irradiation}

The length distribution of DNA fragments after irradiation with e. g. C or Ca with an inhomogeneous spatial double strand breackage probability depends on the detailed folding topology of the chromatin fiber and the RW/GL and MLS models differ largely.

Experiments always agree best with the MLS model independent of the irradiation conditions.

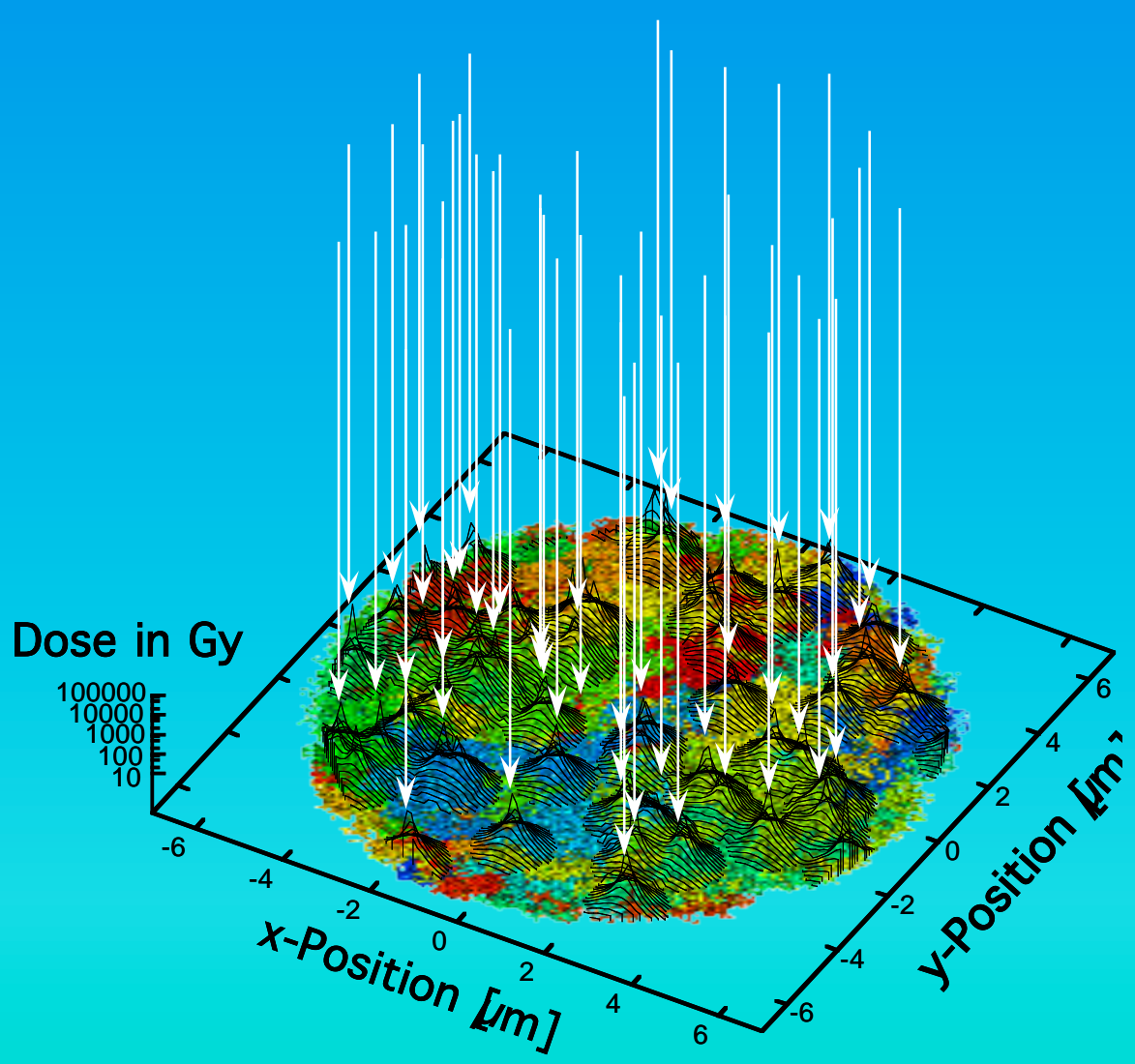




\section{DNA Fragment Distribution after Ione-Irradiation}

The length distribution of DNA fragments after irradiation with e. g. C or Ca with an inhomogeneous spatial double strand breackage probability depends on the detailed folding topology of the chromatin fiber and the RW/GL and MLS models differ largely.

Experiments always agree best with the MLS model independent of the irradiation conditions.
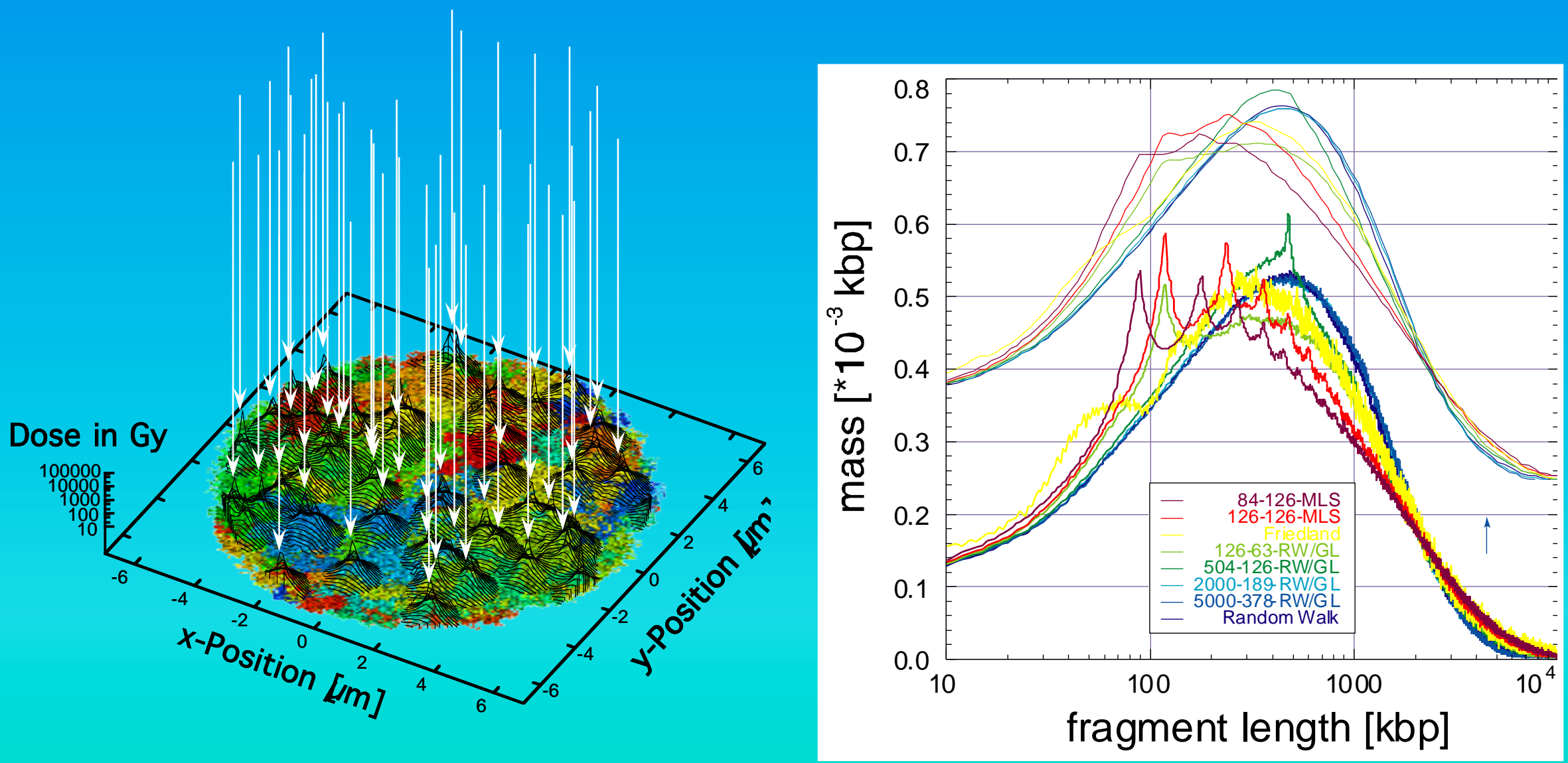


\section{Diffusion of Particles in the Nucleus}

Due to the volume and spatial relation ships in the nucleus typical particles reach almost any location in the nucleus by moderately obstructed diffusion: a $10 \mathrm{~nm}$ particle moves 1 to $2 \mu \mathrm{m}$ within $10 \mathrm{~ms}$.

The structural influence on the obstruction degree is random for Alexa 568 as function of the chromatin distribution visualized by H2A CFP in vivo and measured by fluorescence correlation spectroscopy (FCS)

$$
\left\langle r^{2}\right\rangle \propto t^{2 / D_{w}}
$$

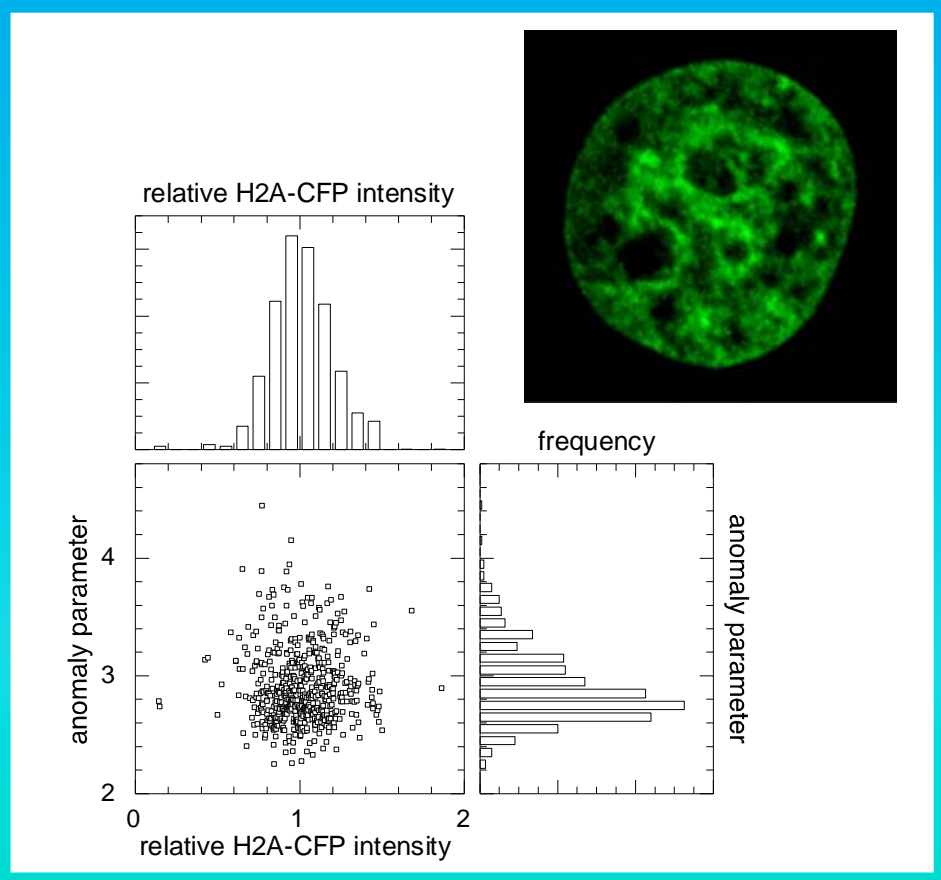

$\begin{array}{ccccc}\begin{array}{c}\text { Nuclear } \\ \text { diameter } \\ {[\mu \mathrm{m}]}\end{array} & \begin{array}{c}\text { Nuclear } \\ \text { Volume } \\ {\left[\mu \mathrm{m}^{3}\right]}\end{array} & \begin{array}{c}\text { Mean Nucloesome } \\ \text { Concentration } \\ {[\mu \mathrm{M}]}\end{array} & \begin{array}{c}\text { Chromatin Volume } \\ \text { Fraction } \\ {[\%]}\end{array} & \begin{array}{c}\text { Mean Isotropic } \\ \text { Mesh Spacing } \\ {[\mathrm{nm}]}\end{array} \\ 6 & 115 & 251 & 20.1 & 41 \\ 8 & 268 & 107 & 8.6 & 64 \\ 10 & 523 & 55 & 4.4 & 90 \\ 12 & 904 & 32 & 2.6 & 117\end{array}$

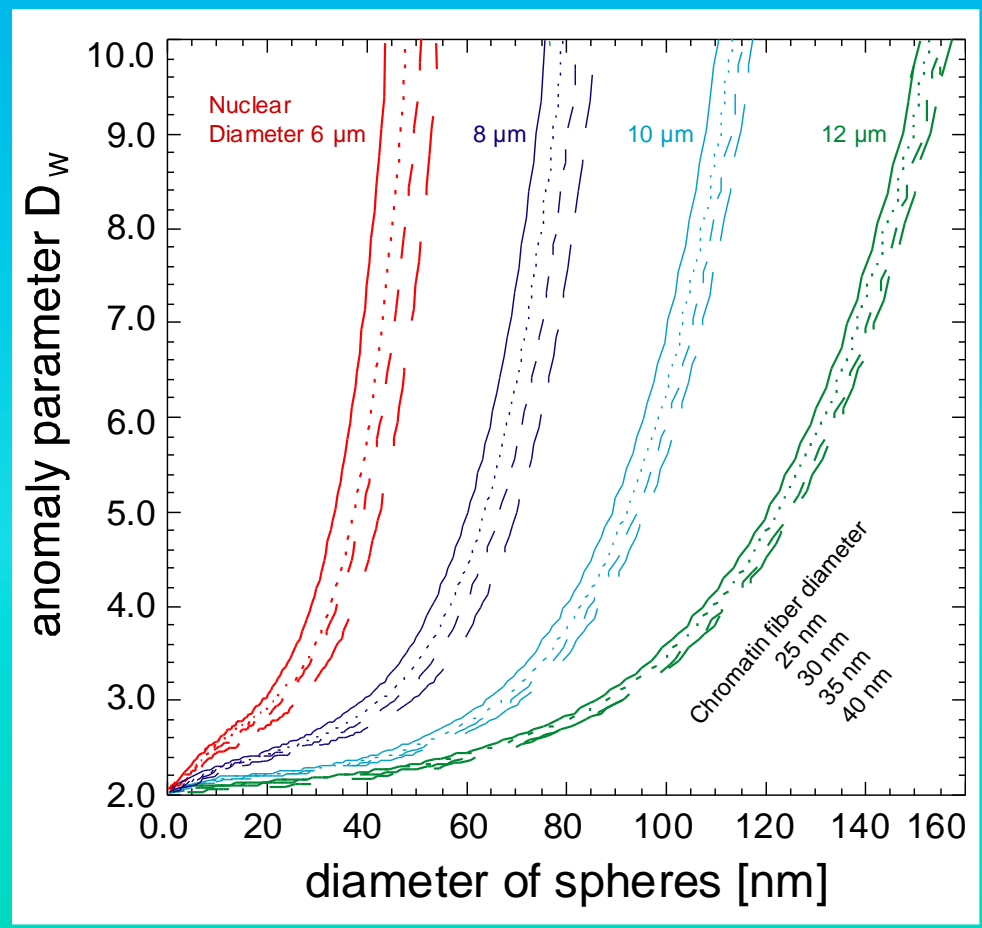




\section{Sequential Organization of Genomes}

Determination of the concentration fluctuation function C(I) and its local slope the correlation coeficient $\delta(\mathrm{l})$ reveal multi-scaling long-range correlation up to $10^{6}$ to $10^{7} \mathrm{bp}$ in Homo sapiens which clearly deviate from random sequences with high significance (decreasing the nearer to the cut-off).

On large scales this might only be due to a strong and definite three-dimensional genome organization.

$$
C(l)=\sqrt{\left\langle\left(c_{l}-\bar{c}_{L}\right)^{2}\right\rangle_{s}}
$$

$$
C(l)=\sqrt{\frac{1}{L-l+1} \sum_{s=1}^{L-l}\left(\frac{1}{l} \sum_{k=1}^{l} n-\frac{1}{L} \sum_{k=1}^{L} N\right)^{2}} \text { numerically stable }
$$
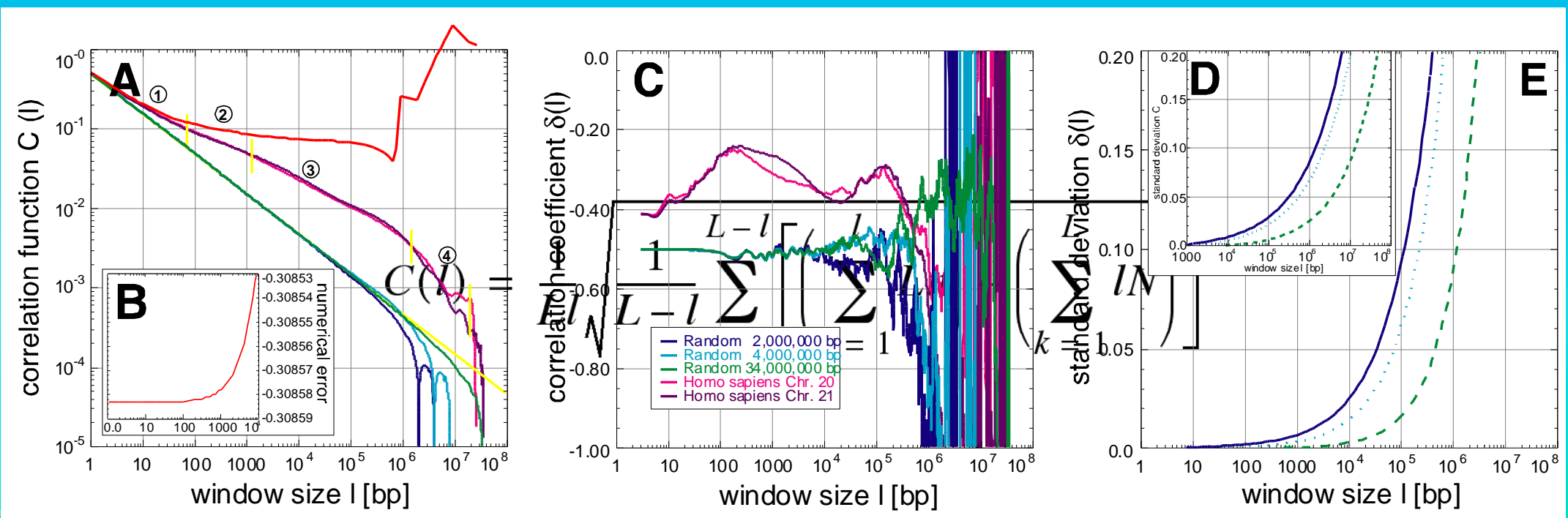


\section{Fine-Structured Multi-Scaling Long-Range \\ Correlations of Homo sapiens}

The general behaveour is characterized by first maximum of the correlation coefficient $d(I)$ at $\sim 250$ bp and at

$1 \times 10^{5}$ to $3 \times 10^{5} \mathrm{bp}$, both due to a globular block structure of genomes. Due to their fine structure the first is attributable to nucleosomal binding and the latter due to aggregation of chromatin loops as in the MLS model.

Thus, the sequential organization is closely connected to the three-dimensional organization of genomes.

general behaviour

fine structure
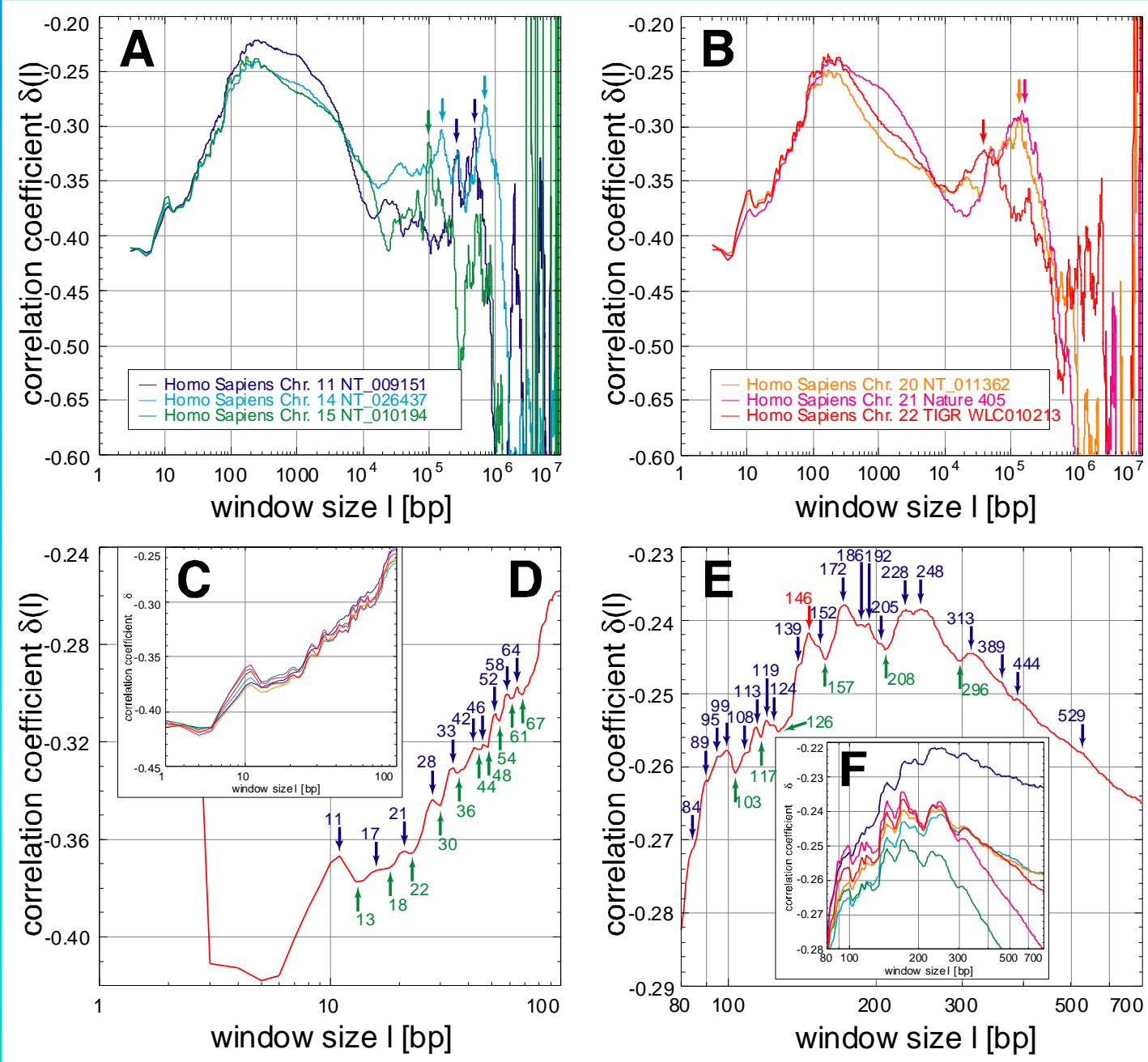

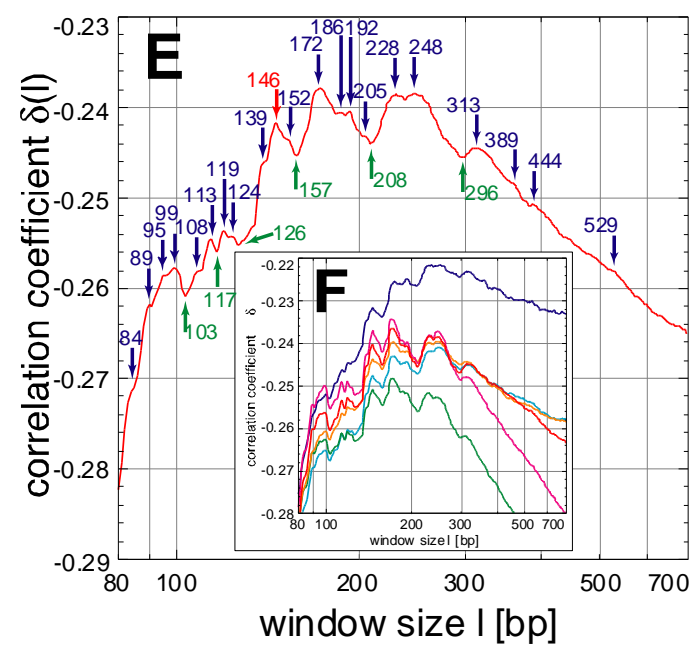

the fine structure survives averaging over several human chromosomes. 


\section{Conclusion}

$>\quad$ Only the MLS model leads to chromosome territories with subcompartments agreeing qualitatively and quantitatively with experiments.

$>\quad$ Comparison between simulated and experimental spatial distances between genetic markers favours and MLS model with 80 to $120 \mathrm{kbp}$ loops and linkers.

$>\quad$ The nuclear morphology or chromatin distribution is tightly connected to the folding topology of the chromatin fiber.

$>\quad$ Scaling analysis of the chromatin fiber topology and nuclear morphology reveals a finestructured multi-scaling behaveour and allows a detailed description model changes.

$>\quad$ Most biological particles (molecules, proteins...) could reach almost any location in the nucleus by only moderately obstructed diffusion in agreement with in vivo experiments.

$>\quad$ The DNA fragment distribution after ion irradiation reflects the chromatin fiber topology not only in detail but also favours always an MLS model.

$>\quad$ The sequential organization of genomes is characterized by fine-structured multi-scaling long-range correlations, which are specie specific and tightly connected to the threedimensional organization of genomes. On large-scales again an MLS model is favoured. 


\section{Acknowledgements}

\section{Biophysics of Macromolecules \\ DKFZ \\ Thomas Weidemann \\ Gabriele Müller \\ Waldemar Waldeck \\ Jörg Langowski}
Karlsruhe
Rudolph Lohner

Supercomputin Center
Molecular Biophysics

KIP

Katalin Fejes-Toth

Malte Wachsmuth

Karsten Rippe

\section{Biomedical Structure Analysis}

DKFZ

\section{Felix Bestvater}

Eberhard Spiess

\section{Molecular Genetics \\ DKFZ}

\author{
Karsten Richter \\ Peter Lichter \\ LMU Munich \\ Peter Quichen \\ Anna Friedl \\ University Tübinge
Markus Göker,
}

The Cremer Labs

Joachim Rauch

Irina Solovei

Michael Hausmann

Christoph Cremer

Thomas Cremer

Scripps Research
Institute

Karin Monier

Kevin Sullivan

Others from the DKFZ:

Monika Stöhr, Michael Stöhr, Andreas Hunziker, Angel Alonso

High-Performance Computing Center Stuttgart, University of Stuttgart; Supercomputing Center Karlsruhe, University of Karlsruhe; Computing Center, Deutsches Krebsforschungszentrum Heidelberg (DKFZ)

Bundesministerium für Forschung und Technology (BMFT) 01 KW 9602/2 (3D-Human Genome Study Group Heidelberg, German Human Genome Projekt)

Deutsches Krebsforschungszentrum (DKFZ) 


\title{
Towards a Holistic Understanding of the Human Genome by Determination and Integration of its Sequential and Three-Dimensional Organization.
}

\author{
Knoch, T. A. \\ Erasmus Medical Center, Erasmus University of Rotterdam, Rotterdam, The Netherlands, \\ 19th August, 2003.
}

\begin{abstract}
To approach the three-dimensional organization of the human cell nucleus, the structural-, scaling- and dynamic properties of interphase chromosomes and cell nuclei were simulated with Monte Carlo and Brownian Dynamics methods. The $30 \mathrm{~nm}$ chromatin fiber was folded according to the Multi-Loop-Subcompartment (MLS) model, in which $\sim 100 \mathrm{kbp}$ loops form rosettes, connected by a linker, and the Random-Walk/Giant-Loop (RW/GL) topology, in which 1-5 Mbp loops are attached to a flexible backbone. Both the MLS and the RW/GL model form chromosome territories but only the MLS rosettes result in distinct subcompartments visible with light microscopy and low overlap of chromosomes, -arms and subcompartments. This morphology and the size of subcompartments agree with the morphology found by expression of histone autofluorescent protein fusions and fluorescernce in situ hybridization (FISH) experiments. Even small changes of the model parameters induced significant rearrangements of the chromatin morphology. Thus, pathological diagnoses based on this morphology, are closely related to structural changes on the chromatin level. The position of interphase chromosomes depends on their metaphase location, and suggests a possible origin of current experimental findings. The chromatin density distribution of simulated confocal (CLSM) images agrees with the MLS model and with recent experiments. The scaling behaviour of the chromatin fiber topology and morphology of CLSM stacks revealed fine-structured multi-scaling behaviour in agreement with the model prediction. Review and comparison of experimental to simulated spatial distance measurements between genomic markers as function of their genomic separation also favour an MLS model with loop and linker sizes of 63 to $126 \mathrm{kbp}$. Visual inspection of the morphology reveals also big spaces allowing high accessibility to nearly every spatial location, due to the chromatin occupancy $<30 \%$ and a mean mesh spacing of 29 to $82 \mathrm{~nm}$ for nuclei of 6 to $12 \mu \mathrm{m}$ diameter. The simulation of diffusion agreed with this structural prediction, since the mean displacement for 10 $\mathrm{nm}$ sized particles of $\sim 1$ to $2 \mu \mathrm{m}$ takes place within $10 \mathrm{~ms}$. Therefore, the diffusion of biological relevant tracers is only moderately obstructed, with the degree of obstruction ranging from 2.0 to 4.0 again in experimental agreement.
\end{abstract}

Corresponding author email contact: TA.Knoch@ taknoch.org

\section{Keywords:}

Genome, genomics, genome organization, genome architecture, structural sequencing, architectural sequencing, systems genomics, coevolution, holistic genetics, genome mechanics, genome function, genetics, gene regulation, replication, transcription, repair, homologous recombination, simultaneous co-transfection, cell division, mitosis, metaphase, interphase, cell nucleus, nuclear structure, nuclear organization, chromatin density distribution, nuclear morphology, chromosome territories, subchromosomal domains, chromatin loop aggregates, chromatin rosettes, chromatin loops, chromatin fibre, chromatin density, persistence length, spatial distance measurement, histones, H1.0, H2A, H2B, H3, H4, mH2A1.2, DNA sequence, complete sequenced genomes, molecular transport, obstructed diffusion, anomalous diffusion, percolation, long-range correlations, 
fractal analysis, scaling analysis, exact yard-stick dimension, box-counting dimension, lacunarity dimension, local nuclear dimension, nuclear diffuseness, parallel super computing, grid computing, volunteer computing, Brownian Dynamics, Monte Carlo, fluorescence in situ hybridization, confocal laser scanning microscopy, fluorescence correlation spectroscopy, super resolution microscopy, spatial precision distance microscopy, autofluorescent proteins, CFP, GFP, YFP, DsRed, fusionprotein, in vivo labelling.

\section{Literature References}

Knoch, T. A. Dreidimensionale Organisation von Chromosomen-Domänen in Simulation und Experiment. (Three-dimensional organization of chromosome domains in simulation and experiment.) Diploma Thesis, Faculty for Physics and Astronomy, Ruperto-Carola University, Heidelberg, Germany, 1998, and TAK Press, Tobias A. Knoch, Mannheim, Germany, ISBN 3-00-010685-5 and ISBN 978-3-00-010685-9 (soft cover, 2rd ed.), ISBN 3-00-035857-9 and ISBN 978-3-00-0358857-0 (hard cover, 2rd ed.), ISBN 3-00035858-7, and ISBN 978-3-00-035858-6 (DVD, 2rd ed.), 1998.

Knoch, T. A., Münkel, C. \& Langowski, J. Three-dimensional organization of chromosome territories and the human cell nucleus - about the structure of a self replicating nano fabrication site. Foresight Institute Article Archive, Foresight Institute, Palo Alto, CA, USA, http://www. foresight.org, 1- 6, 1998.

Knoch, T. A., Münkel, C. \& Langowski, J. Three-Dimensional Organization of Chromosome Territories and the Human Interphase Nucleus. High Performance Scientific Supercomputing, editor Wilfried Juling, Scientific Supercomputing Center (SSC) Karlsruhe, University of Karlsruhe (TH), 27- 29, 1999.

Knoch, T. A., Münkel, C. \& Langowski, J. Three-dimensional organization of chromosome territories in the human interphase nucleus. High Performance Computing in Science and Engineering 1999, editors Krause, E. \& Jäger, W., High-Performance Computing Center (HLRS) Stuttgart, University of Stuttgart, Springer Berlin-Heidelberg-New York, ISBN 3-540-66504-8, 229-238, 2000.

Bestvater, F., Knoch, T. A., Langowski, J. \& Spiess, E. GFP-Walking: Artificial construct conversions caused by simultaneous cotransfection. BioTechniques 32(4), 844-854, 2002.

Knoch, T. A. (editor), Backes, M., Baumgärtner, V., Eysel, G., Fehrenbach, H., Göker, M., Hampl, J., Hampl, U., Hartmann, D., Hitzelberger, H., Nambena, J., Rehberg, U., Schmidt, S., Weber, A., \& Weidemann, T. Humanökologische Perspectiven Wechsel - Festschrift zu Ehren des 70. Geburtstags von Prof. Dr. Kurt Egger. Human Ecology Working Group, Ruperto-Carola University of Heidelberg, Heidelberg, Germany, 2002.

Knoch, T. A. Approaching the three-dimensional organization of the human genome: structural-, scaling- and dynamic properties in the simulation of interphase chromosomes and cell nuclei, long- range correlations in complete genomes, in vivo quantification of the chromatin distribution, construct conversions in simultaneous co-transfections. Dissertation, Ruperto-Carola University, Heidelberg, Germany, and TAK†Press, Tobias A. Knoch, Mannheim, Germany, ISBN 3-00-009959-X and ISBN 978-3-00-009959-5 (soft cover, 3rd ed.), ISBN 3-00-009960-3 and ISBN 978-3-00-009960-1 (hard cover, 3rd ed.), ISBN 3-00035856-9 and ISBN 978-3-00-010685-9 (DVD, 3rd ed.) 2002.

Knoch, T. A. Towards a holistic understanding of the human genome by determination and integration of its sequential and three-dimensional organization. High Performance Computing in Science and Engineering 2003, editors Krause, E., Jäger, W. \& Resch, M., High-Performance Computing Center (HLRS) Stuttgart, University of Stuttgart, Springer Berlin-Heidelberg-New York, ISBN 3- 540-40850-9, 421-440, 2003.

Wachsmuth, M., Weidemann, T., Müller, G., Urs W. Hoffmann-Rohrer, Knoch, T. A., Waldeck, W. \& Langowski, J. Analyzing intracellular binding and diffusion with continuous fluorescence photobleaching. Biophys. J. 84(5), 3353-3363, 2003. 
Weidemann, T., Wachsmuth, M., Knoch, T. A., Müller, G., Waldeck, W. \& Langowski, J. Counting nucleosomes in living cells with a combination of fluorescence correlation spectroscopy and confocal imaging. J. Mol. Biol. 334(2), 229-240, 2003.

Fejes Tóth, K., Knoch, T. A., Wachsmuth, M., Frank-Stöhr, M., Stöhr, M., Bacher, C. P., Müller, G. \& Rippe, K. Trichostatin A induced histone acetylation causes decondensation of interphase chromatin. J. Cell Science 177, 4277-4287, 2004.

Ermler, S., Krunic, D., Knoch, T. A., Moshir, S., Mai, S., Greulich-Bode, K. M. \& Boukamp, P. Cell cycledependent 3D distribution of telomeres and telomere repeat-binding factor 2 (TRF2) in HaCaT and HaCaTmyc cells. Europ. J. Cell Biol. 83(11-12), 681-690, 2004. 